\title{
BMJ Open Magnitude of premenstrual dysphoric disorder and its correlation with academic performance among female medical and health science students at University of Gondar, Ethiopia, 2019: a cross-sectional study
}

\author{
Woredaw Minichil (D) , Eleni Eskindir, Demeke Demilew (D) , Yohannes Mirkena
}

To cite: Minichil W, Eskindir E, Demilew D, et al. Magnitude of premenstrual dysphoric disorder and its correlation with academic performance among female medical and health science students at University of Gondar, Ethiopia, 2019: a crosssectional study. BMJ Open 2020;10:e034166. doi:10.1136/ bmjopen-2019-034166

- Prepublication history for this paper is available online To view these files, please visit the journal online (http://dx.doi org/10.1136/bmjopen-2019034166).

Received 19 September 2019 Revised 12 May 2020 Accepted 03 June 2020

\section{D) Check for updates}

(c) Author(s) (or their employer(s)) 2020. Re-use permitted under CC BY-NC. No commercial re-use. See rights and permissions. Published by BMJ.

Psychiatry, University of Gondar College of Medicine and Health Sciences, Gondar, Ethiopia

Correspondence to

Dr Woredaw Minichil; woredawm21@gmail.com

\section{ABSTRACT}

Objective To assess the magnitude of premenstrual dysphoric disorder (PMDD) and associated factors among female students of the College of Medicine and Health Sciences, University of Gondar, Gondar, Ethiopia, 2019. Design Institution-based cross-sectional study design. Setting College of Medicine and Health Sciences, University of Gondar, Gondar, Ethiopia.

Participants 386 participants were recruited for selfadministered interview using the stratified followed by simple random sampling technique.

Measurement Data were collected by self-administered interview. Diagnostic and Statistical Manual of Mental Disorders, fifth edition (DSM-5) was used to measure PMDD. The Perceived Stress Scale (PSS) and the 0slo-3 social support are used to assess the factors. The data were checked, cleaned and entered into EpiData V.3.1 and exported to Statistical Package for Social Science (SPSS) V.21.0 for analysis. Bivariate and multivariable binary logistic regressions were used. OR with $95 \% \mathrm{Cl}$ was employed to see the strength of associations between dependent and independent variables. Variables with a $p$ value $<0.05$ in multivariable logistic regression were declared as significantly associated.

Result 386 participants were involved in the study, with a response rate of $84.6 \%$. The overall magnitude of PMDD in this study was $34.7 \%$ (30.3 to 39.1). Severe menstrual pain $($ adjusted OR $(\mathrm{AOR})=2.82,95 \% \mathrm{Cl}: 1.83$ to 4.23$)$, perception of an impact on academic performance due to menstrual pain ( $\mathrm{AOR}=2.31,95 \% \mathrm{Cl}: 1.23$ to 4.32 ), and high perceived stress (AOR=3.52, 95\% Cl: 2.58 to 5.60 ) were significantly associated with PMDD disorder among female medical and health sciences students.

Conclusion PMDD is high among female medical and health sciences students. Thus, it needs early screening and intervention especially for those who have severe menstrual pain, perceived to have an impact on academic performance and high perceived stress.

\section{INTRODUCTION}

Menstruation is the reproductive process whereby the upper two-thirds of the

\section{Strengths and limitations of this study}

- We used an adequate sample for the study using appropriate sampling technique and data collection procedure.

- Since the study design was cross-sectional, it could not establish the temporal association between premenstrual dysphoric disorder and identified risk factors.

- The severity of pain was retrospective self-reported and therefore it may be subjected to social desirability and recall bias which is common to all questionnaires-based studies as to what one regards as moderate might be regarded as mild or severe by another.

- Comorbid mental illness was not assessed so that students with mental health problem might present symptoms overlapping with the symptoms of premenstrual syndrome.

endometrium is shed and regenerated on a repetitive basis. ${ }^{1}$ Physical or emotional symptoms are experienced by a majority of women of reproductive age group before the onset of menstruation. ${ }^{2}$

More than 200 premenstrual symptoms have been known over the last 50 years, which include three main emotional, behavioural and physical domains. ${ }^{3}$ It is indicated that three out of every four women may experience slight physical and mental disorders before menstruation. Seventy-five per cent of women with regular menstrual cycles experience symptoms of premenstrual syndrome (PMS), while premenstrual dysphoric disorder (PMDD) affects only 3\% to $8 \%$ of women in this group. ${ }^{4}$

Among women samples, up to $85 \%$ have reported one or more premenstrual 
symptoms. ${ }^{5}$ Worldwide prevalence shows that $5 \%$ to $20 \%$ of women of reproductive age have moderate-to-severe premenstrual complaints and up to $75 \%$ of all women of reproductive age may experience symptoms of PMS. PMS, which is characterised by one or more physical, emotional or behavioural symptoms during the days before menstruation, was found in $94.8 \%$ of women of reproductive age (15 to 49 years). ${ }^{6}$ In India, it was shown that $12.2 \%$ had PMDD and $67 \%$ were not interested in going to school during menstruation, and $71 \%$ reported lack of concentration during study hours. ${ }^{7}$ Different community-based surveys showed that the point prevalence of PMDD among women across the globe ranged from $1.2 \%$ to $6.4 \% \cdot{ }^{8-10} \mathrm{~A}$ Nigerian study also stated that PMDD prevalence in the country was $36.1 \% .^{11}$ The studies conducted in other universities of Ethiopia showed that the prevalence of PMDD ranged from $13.8 \%$ to $66.9 \%$ among medical and health science students. ${ }^{12-14}$

PMS can harm the interpersonal relationship, daily activity, work productivity and the overall physical health of a woman. ${ }^{15}$ Even though most women with PMS are able to perform their day-to-day activities; in its severe form, this disorder has been associated with increased absenteeism from school and work, poor academic performance, high suicidal ideation and attempt, and acute mental health problems. ${ }^{16-18}$ Some students find it difficult to get out of bed and attend class on time, sudden mood swings also make it difficult to cope with the consequences that come after that. If PMS is left untreated, and when women face other environmental or personal stress, the symptoms increase and the severity worsens, forming a mental disorder called PMDD. ${ }^{19-21}$ PMDD is the severest form of PMS spectrum where physical and emotional symptoms are more common. ${ }^{7}$

Chronic stress is known to be a prominent factor in the prevalence and severity of premenstrual symptoms. Stress has been associated with a significant amount of variation in psychological, emotional and physical wellbeing. ${ }^{22}$ Different studies have indicated that PMS is more common and more severe among well-educated women than uneducated women with a possible association of PMS with stress. ${ }^{23} 24$ Severe PMS/PMD is said to be more common in the late twenties and mid-thirties. ${ }^{25} 26$ Two hundred and twenty-nine $(68.8 \%)$ respondents with mild/moderate symptoms were less than 25 years old, and so were $68.0 \%$ of those with severe/extreme symptoms. ${ }^{6}$ Dysmenorrhoea had statistically significant association with PMDD. ${ }^{14-29}$ Older age groups, average length of one cycle of menstruation and academic performance impairment, rural residence, lower age at menarche, regularity of menses and family history of menstrual related problem were associated with PMDD in other studies. ${ }^{30-32}$

Even though PMDD has a high impact on academic performance, special attention still is not given for premenstrual-related problems in Ethiopia. Female university students are highly vulnerable to stress and impairments including social, occupational or other important areas of functioning, and this also affects their academic performance, especially prior to their menstruation. If these premenstrual related problems are left untreated, they increase in number and severity, and then can form a mental disorder called PMDD which is a severe form of PMS. Therefore, the result of this study was intended for alarming concerned bodies to develop appropriate policies, strategic plans and intervention programmes to screen and treat such premenstrualrelated problems early. This also aids to minimise or eliminate its negative effect on academic achievement.

\section{Objective}

The aim of this study was to assess the magnitude of PMDD and associated factors among medical and health science students at the College of Medicine and Health Sciences, University of Gondar, Gondar, Ethiopia.

\section{METHODS AND MATERIALS \\ Study design and period}

An institution-based cross-sectional study was conducted among female undergraduate students at the University of Gondar, College of Medicine and Health Sciences from May to June, 2019.

\section{Study participants and sampling procedure}

We used stratified, by considering years of study as strata, followed by simple random sampling technique to recruit 456 female undergraduates. Sample frame was prepared by using their identification numbers taking from registrar office. All female undergraduate students were our source populations, and students who were sampled were the study populations. Female undergraduates who were enrolled in the first semester of 2018/2019 academic year and attending their education were included in the study. Students who were using hormonal contraceptive, pregnant and had follow-up treatment for known physical and mental disorder were excluded.

\section{Sample size determination}

The sample size of this study was determined by using the single population proportion formula by assuming $66.9 \%$ prevalence of PMDD among female health science students from the study conducted at Wollo University, Ethiopia, ${ }^{14} 1.96 \mathrm{Z}$ (standard normal distribution), $4 \%$ tolerable margin of error, $95 \% \mathrm{CI}$ of certainty (alpha $=0.05)$ and $10 \%$ non-response rate.

$$
\mathrm{n}=(\mathrm{z} \alpha / 2)^{2} \cdot \mathrm{p}(1-\mathrm{p}) / \mathrm{d}^{2}
$$

$\mathrm{n}=$ minimum sample size required

$\mathrm{p}=$ proportion of PMDD in previous study $(66.9 \%)$

$\mathrm{d}=$ tolerable margin of error $(4 \%)$

$\frac{z \alpha}{2}=$ standard normal distribution, 1.96 and, commonly $\alpha=5 \%$ with $95 \%$ CI

$$
\begin{aligned}
\mathrm{n} & =(1.92)^{2} \cdot 0.669(1-0.669) / 0.04^{2} \\
& =532
\end{aligned}
$$


But the number of female students in the University of Gondar, College of Medicine and Health Sciences was 1879 , which is less than 10000 , during the study year; so, we have used correction formula to calculate the final sample size (nf).

$$
\begin{aligned}
\mathrm{nf} & =\frac{\mathrm{n}}{1+\mathrm{n} / \mathrm{N}} \\
\mathrm{nf}= & \frac{532}{1+532 / 1879} \\
& =414
\end{aligned}
$$

By adding $10 \%$ non-response, the final sample size was 456.

\section{Study variables}

Outcome variable was PMDD which was assessed by Diagnostic and Statistical Manual of Mental Disorders, fifth edition (DSM-5). PMDD was treated as categorical variable (Yes/No). Independent variables included socio-demographic factors (age, religion, ethnicity, marital status, residence and mothers' educational level), obstetric and gynaecologic factors (menstrual duration in one cycle and its regularity, premenstrual pain and its level, age at menarche, family history of menstrual-related problem and impact on academic performance), psychosocial factors such as social support and academic stress were assessed, and substance-related factors (alcohol, khat and cigarette).

\section{Measurement}

Data were collected from female medical and health science students using self-administered and semistructured questionnaire by psychiatric nurses using the Amharic version of the tool for 10 days. The questionnaire was translated from English to local language (Amharic) before data collection and back to English to maintain its consistency. Training was given for data collectors on how to approach and explain unclear questions, and the purpose of the study. The questionnaire was tested on $5 \%$ of the total sample before the actual data collection was started and its finding was not included in the main research report. Data collectors were made aware of ethical principles like confidentiality and security of informed consent.

PMDD was measured by DSM-5. DSM-5 was developed by the American Psychiatric Association and currently is used to diagnose clinical PMDD in Ethiopia. Those women experiencing at least five symptoms from diagnostic criteria of DSM-5 in the majority of menstrual cycles were considered as having PMDD. It was must for these symptoms to be present in the final week before the onset of menses, start to improve within a few days after the onset of menses, and become minimal or absent in the week of post menses. ${ }^{33}$

\section{Social support}

Social support was assessed by using the Oslo 3-item social support scale which had a sum score range from 3 to 14 and had three broad categories. According to this category, respondents who scored between 3 and 8,9 and 11 , and 12 and 14 were considered as having poor, moderate and strong social support, respectively. ${ }^{34}$ In the current study, its Cronbach's alpha was 0.79 , refers good reliability.

\section{Perceived stress}

In order to measure individual stress levels, Perceived Stress Scale-10 item (PSS-10) was used, which was found to be very reliable for determining the role of stress in the aetiology of psychological and behavioural disorders. Based on PSS-10, scores ranging from 0 to 13 were considered to indicate low perceived stress; 14 to 26 moderate perceived stress, and 27 to 40 high perceived stress. ${ }^{35}$ Its reliability was tested with a Cronbach's alpha of 0.88 .

\section{Data processing and analysis}

Data were coded and entered in the computer using EpiData V.3.1, and exported to the Statistical Package for Social Science (SPSS) V. 21 for analysis. After data cleaning, bivariate analysis was used to assess the associations between dependent and predictive variables. Adjusted OR (AOR) with 95\% CI was used to estimate the strength of the association. AOR is the statistical value that is found during multivariate analysis (after controlling the confounding effects). All variables associated with PMDD, at a $p$ value $<0.05$ in the bivariate logistic regression, were further analysed using multivariate logistic regression analyses to control confounding effects. Variables with a $p$ value $<0.05$ in the multivariable binary logistic regression were declared to be significantly associated with PMDD.

\section{Patient and public involvement}

Participants in the current study were medical and health science students at the College of Medicine and Health Sciences, University of Gondar, Ethiopia. Patients were already excluded in our methods. Respondents were not involved in the design of the study and recruitment. The result of this study will be disseminated to the University of Gondar, College of Medicine and Health Sciences, gender office and psychiatry department for timely intervention.

\section{RESULT}

Socio-demographic characteristics of the study participants

A total of 456 students were invited to participate in the study. Of those, 386 filled completely and turned back the questionnaire that yielded a response rate of $84.6 \%$. The reason for this low response rate was lack of interest and limited time. The age of participants ranged from 18 to 26 years with a mean age of $20.9 \pm 1.66$ (SD) years. Majority $284(73.6 \%)$ of the participants were orthodox Christian religion followers. Most of the respondents 317 (82.1\%) were single in marital status. Of the total participants, 333 $(86.3 \%)$ came from urban areas before they joined the university. (table 1)

\section{Gynaecological and obstetric-related characteristics}

Of the total respondents, $284(73.6 \%)$ complained of menstrual pain. Of those having menstrual pain, $137(35.5 \%)$ perceived that the menstrual pain has an 
Table 1 Socio-demographic characteristics and their associations with PMDD among female students at the College of Medicine and Health Sciences, University of Gondar, Gondar, Ethiopia, 2019. $(n=386)$

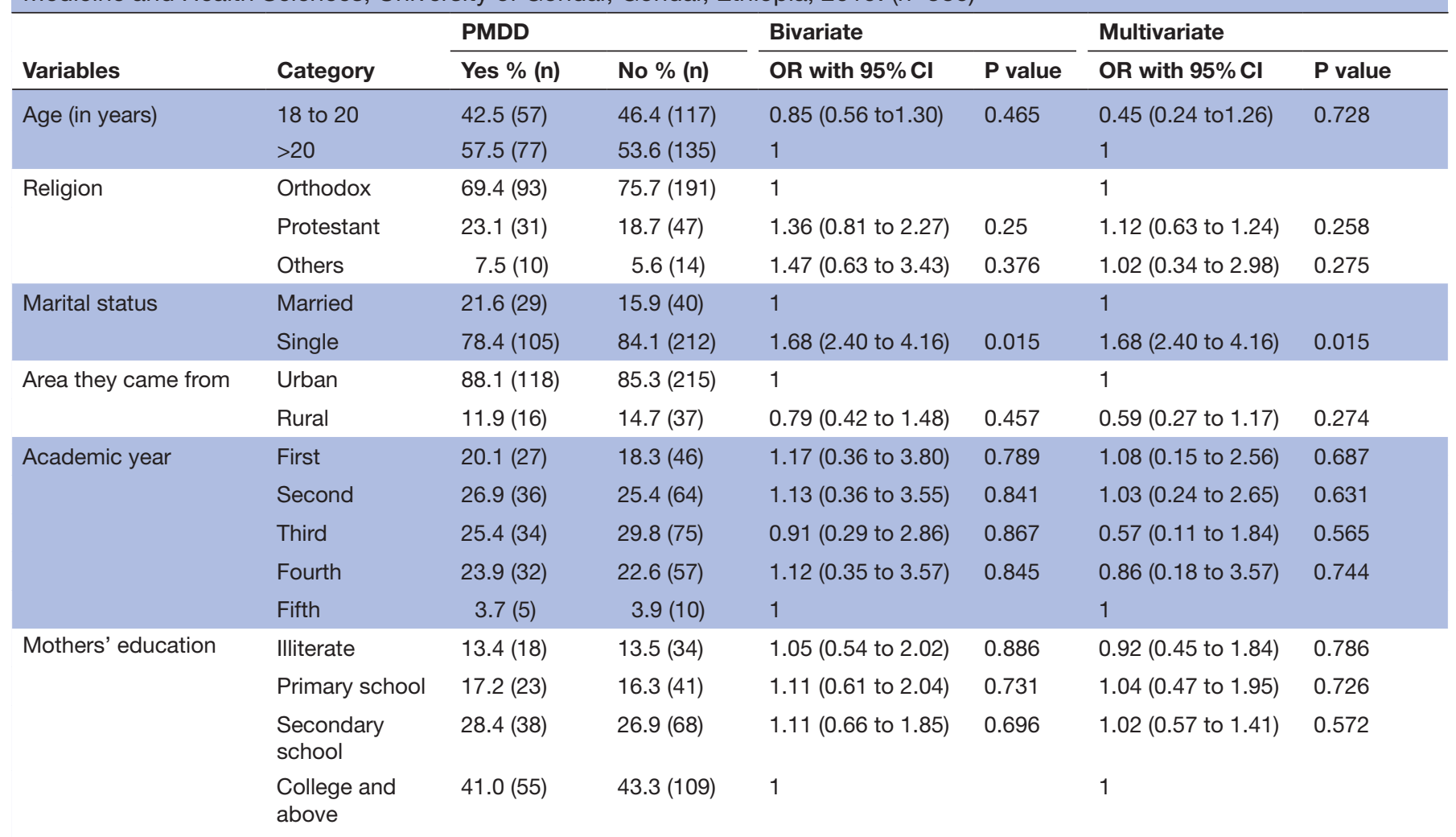

PMDD, premenstrual dysphoric disorder.

impact on their academic performance, and 99 (72.3\%) missed their class at least once in their campus stay. One hundred sixty-six (43\%) respondents had a family history of menstrual-related problems. Of the total respondents, $223(57.8 \%)$ had 4 to 5 days of menstrual bleeding per cycle. Students who had menstrual pain used different pain management techniques; painkillers like paracetamol and ibuprofen $37 \%$, hot drinks such as tea and coffee $51 \%$, and only $7.1 \%$ consulted healthcare providers. (table 2)

\section{Psychosocial and substance-related characteristics}

Regarding psychosocial factors, among the total respondents, $246(63.7 \%)$ had poor social support and 174 $(45.1 \%)$ didn't perceive stress. Of the total respondents, $97(25.1 \%)$, eight $(2.1 \%)$ and four $(1 \%)$ used alcohol, khat and cigarette, respectively, within the last 3 months. (table 3)

\section{Prevalence of PMDD}

In the current study, the magnitude of PMDD among undergraduate students in the University of Gondar, College of Medicine and Health Sciences was $34.7 \%$ with 95\% CI (30.3 to 39.1). The most commonly reported symptom were lethargy, easily fatigability or marked lack of energy (63.5\%), followed by decreased interest in usual activities (58.5\%) (table 4).

\section{Factors associated with PMDD}

In the crude logistic regression analysis, being single, family history of menstrual-related problem, severe menstrual pain, perceiving an impact of menstrual pain on academic performance, high amount of menstrual bleeding per day, moderate-to-high perceived stress, 6 days and above of menstrual bleeding in one cycle, and current use of khat and cigarette were associated with PMDD at a $p$ value $<0.05$. These factors were fitted with adjusted logistic regression for further analysis. In the overall adjusted logistic regression analysis, severe menstrual pain, perceiving an impact on academic performance due to menstrual pain and high perceived stress were significantly associated with PMDD.

The odds of developing PMDD was 2.31 times higher among female students who perceived an impact of menstrual pain on their academic performance than those who did not perceive (AOR=2.31, 95\% CI: 1.23 to 4.32). The odds of developing PMDD was 2.82 times higher among students having severe menstrual pain compared with those who had no menstrual pain (AOR=2.82, 95\% CI: 1.83 to 4.23 ). The odds of developing PMDD was also 3.52 times higher among students who had high perceived stress (AOR $=3.52,95 \%$ CI: 2.58 to 5.60) compared with those who had no such stress (table 5). 
Table 2 PMDD associated with gynaecological and obstetric-related characteristics of students at the College of Medicine and Health Sciences, University of Gondar, Gondar, Ethiopia, 2019. ( $n=386)$

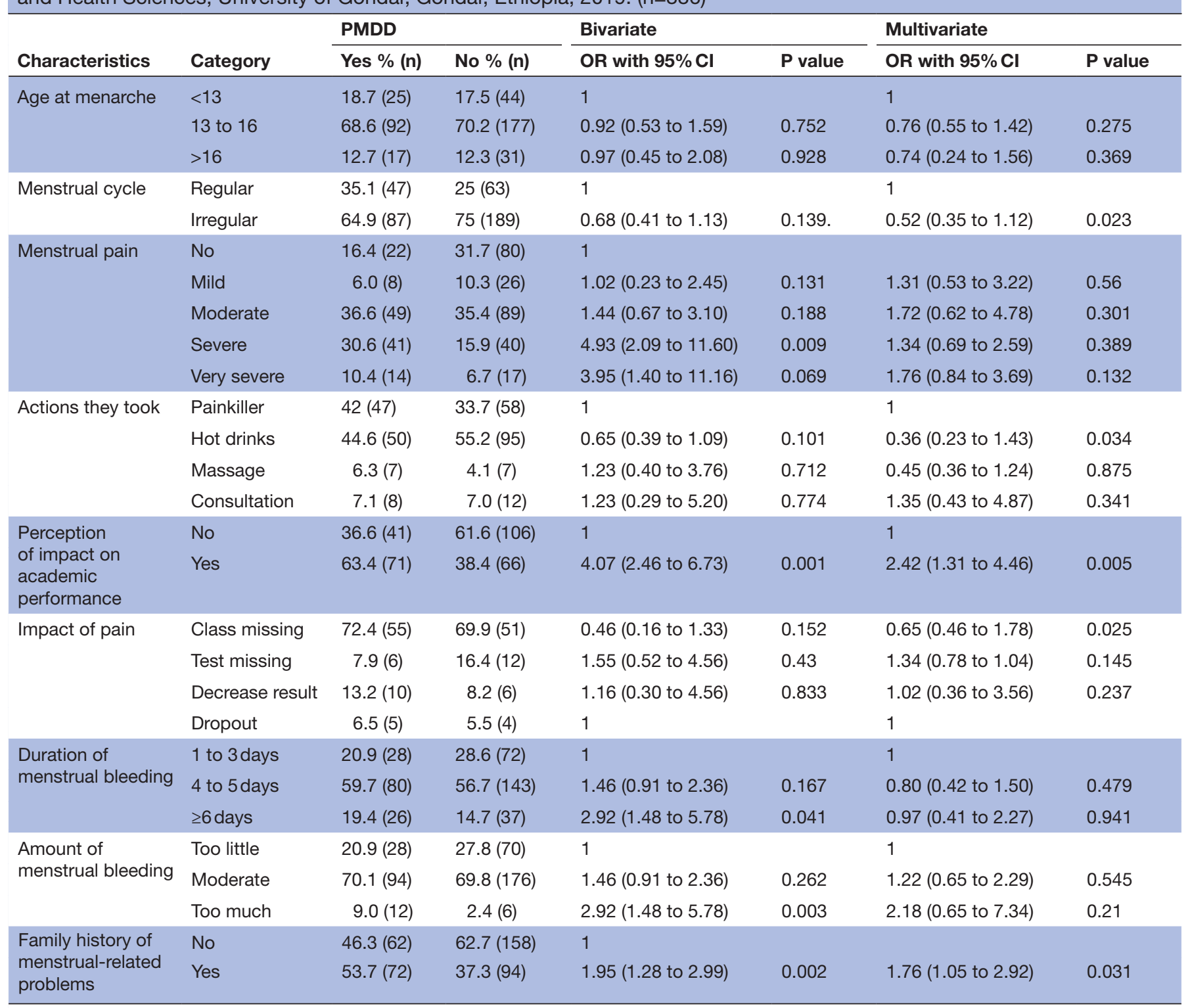

PMDD, premenstrual dysphoric disorder.

\section{DISCUSSION}

Symptoms of PMDD have a negative impact on academic performance of female students. ${ }^{36}{ }^{37}$ Therefore, there is a need to determine the prevalence of PMDD and identify the predictors associated with it. This would also help prevent the problem and prepare treatment strategies that promote the academic performance of female university students.

In the current study, the magnitude of PMDD was marginally similar with studies conducted in another area of Ethiopia at $30.9 \%,{ }^{38}$ Egypt $40.5 \%,{ }^{39}$ Nigeria $36.1 \%,{ }^{11}$ Korea $34.8 \%,{ }^{40}$ Nepal $38.9 \%$ of medical students ${ }^{41}$ and Iran 36.3\%. ${ }^{42}$ However, the magnitude of PMDD in this study was lower than the studies conducted among female students in other parts of Ethiopia at $66.9 \%,{ }^{14} \mathrm{Nepal}$ $39.6 \%$ nursing students ${ }^{41}$ and Iran $59 \%{ }^{43}$ The possible explanation for this difference might be: smaller sample size (254), socio-demographic characteristics, time of data collection (1 to 15 February 2017) and curriculum difference. In Wollo University, Ethiopia, medical students joined the University by losing their work, salary and spousal affiliation, which increases premenstrual-related dysphoric symptoms. The proportion of PMDD in female medical and health science students of University of Gondar was lower than the nursing students of a tertiary care teaching hospital in Nepal. The other probable reason might also be differences in socio-demographic characteristics, level of academic stress, course load and study setting. The prevalence of PMDD in Iranian adolescent schoolgirls was high compared with the current study finding. The possible variation for this difference could be due to tool difference (Premenstrual Assessment Scale 
Open access

Table 3 Associations between PMDD and psychosocial and substance-related characteristics among female students at the College of Medicine and Health Sciences, University of Gondar, Gondar, Ethiopia, 2019. $(n=386)$

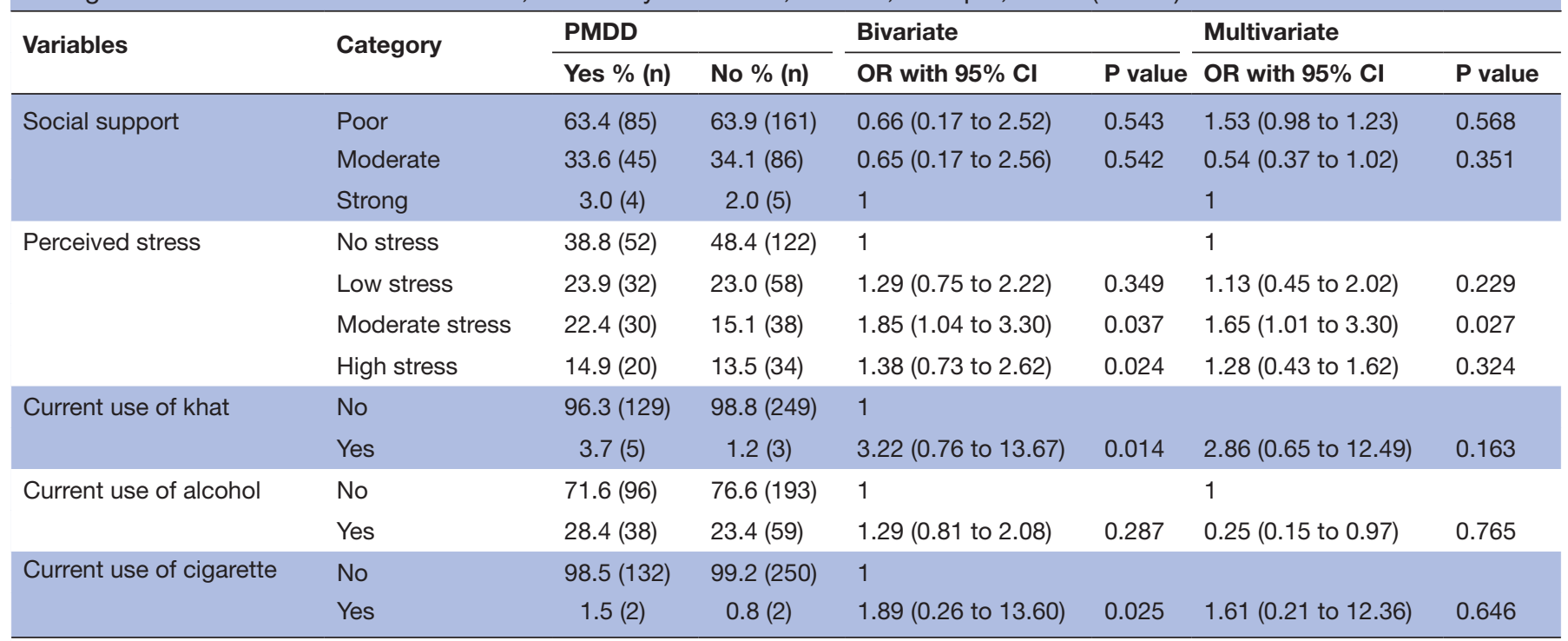

PMDD, premenstrual dysphoric disorder.

(PAS)), sample size (1379), socio-cultural, sampling technique and being young, as the contribution of mixed psychobiological signs and symptoms of premenstrual problem in Iran. On the other hand, the magnitude of PMDD in this study was higher than the studies conducted in other areas of Ethiopia at $13.8 \%,{ }^{12} 26.8 \%{ }^{13}$ and $27 \% ;^{44}$

Table 4 Proportions of premenstrual dysphoric symptoms among students at the College of Medicine and Health Sciences, University of Gondar, Gondar, Ethiopia, 2019. ( $n=386)$ (DSM-5)

\begin{tabular}{|c|c|c|c|}
\hline Item & Category & Frequency (N) & Percentage (\%) \\
\hline \multirow[t]{2}{*}{ Marked affective lability } & No & 201 & 52.1 \\
\hline & Yes & 185 & 47.9 \\
\hline Marked irritability or anger or increased interpersonal conflicts & Yes & 135 & 35 \\
\hline $\begin{array}{l}\text { Marked depressed mood, feelings of hopelessness or self- } \\
\text { deprecating thoughts }\end{array}$ & No & 281 & 72.8 \\
\hline $\begin{array}{l}\text { Marked anxiety, tension, feelings of being 'keyed up' or 'on } \\
\text { edge' }\end{array}$ & Yes & 136 & 35.2 \\
\hline \multirow{2}{*}{$\begin{array}{l}\text { Decreased interest in usual activities (eg, work, school, friends } \\
\text { and hobbies) }\end{array}$} & No & 160 & 41.5 \\
\hline & Yes & 226 & 58.5 \\
\hline Subjective difficulty in concentration & No & 247 & 64 \\
\hline \multirow{2}{*}{$\begin{array}{l}\text { Marked change in appetite, overeating or specific food } \\
\text { cravings }\end{array}$} & No & 260 & 67.4 \\
\hline & Yes & 126 & 32.6 \\
\hline \multirow[t]{2}{*}{ Hypersomnia or insomnia } & No & 203 & 52.6 \\
\hline & Yes & 183 & 47.4 \\
\hline \multirow[t]{2}{*}{ Sense of being overwhelmed or out of control } & No & 320 & 82.9 \\
\hline & Yes & 66 & 17.1 \\
\hline \multirow{2}{*}{$\begin{array}{l}\text { Physical symptoms such as breast tenderness or swelling, } \\
\text { joint or muscle pain, a sensation of "bloating," weight gain }\end{array}$} & No & 168 & 43.5 \\
\hline & Yes & 218 & 56.5 \\
\hline
\end{tabular}

DSM-5, Diagnostic and Statistical Manual of Mental Disorders, fifth edition. 
Table 5 Overall crude and adjusted logistic regression analysis of factors associated with premenstrual dysphoric disorder among female medical and health science students at College of Medicine and Health Sciences, University of Gondar, Gondar, Ethiopia, 2019. $(n=386)$

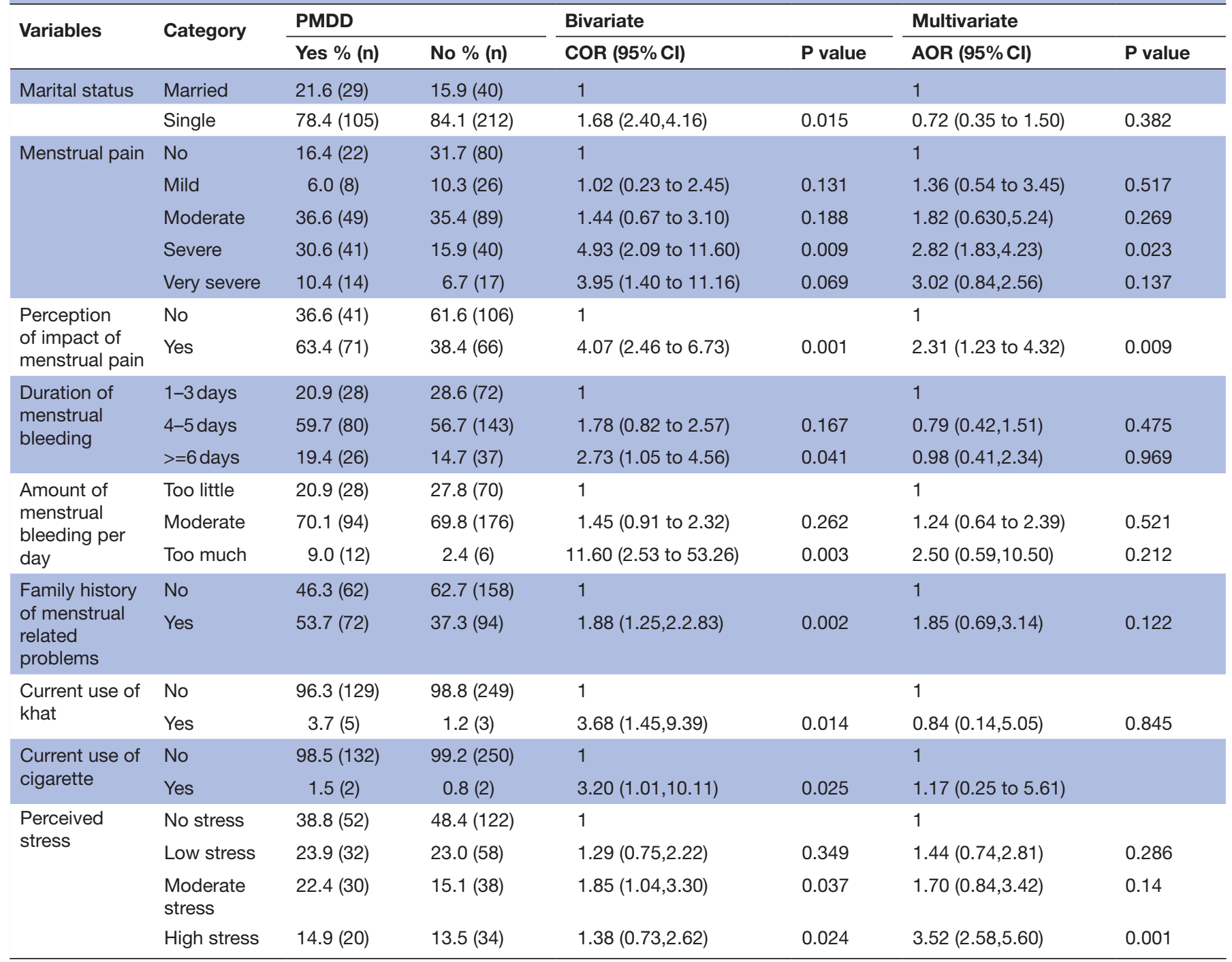

Jordan $7.7 \% ;^{36}$ and India $3.7 \%$ and $12.22 \% .^{45} 46$ In the studies conducted in the other areas of Ethiopia, the prevalence of PMDD was lower than the current study. The possible reason for this difference might be variations in course load, study setting, study subject, diagnostic tool and sample size. The magnitude of PMDD in this study was higher than a prospective study done in Jordan among female university students. The possible reason for this variation might be study design, sociodemographic characteristics, data collection period (at the beginning of a semester in Jordan) and study participants. Different studies showed that the prevalence of PMDD among female students in India was lower than our study finding. The differences could be due to sample size, cross-cultural variation and academic stress (striving for higher academic achievements).

In the current study, the most commonly reported symptoms were lethargy; easily fatigability or marked lack of energy (63.5\%); decreased interest in usual activities
(58.5\%); and physical symptoms such as breast tenderness or swelling, joint or muscle pain, and a sensation of 'bloating' and weight gain $(56.5 \%)$. It was consistent with the study findings indicated in Mekelle University, Ethiopia, ${ }^{12} 3144$ and in Iran ${ }^{42}$ and India. ${ }^{45}$ Sense of being overwhelmed or out of control $17.1 \%$, marked depressed mood, feeling of hopelessness or self-deprecating thoughts $27.2 \%$ were the least prevalent symptoms.

Students perceiving an impact of menstrual pain on academic performance were more likely to develop PMDD than those who didn't perceive such impact. The possible reason might be due to the fact that participants with the perception of an impact on academic performance become more concerned and hypervigilant with the premenstrual symptoms that led to difficulty concentrating, missing class, dysmenorrhoea (menstrual pain) and dropout/failure in academics. This was supported by studies conducted in other areas of Ethiopia and the Kingdom of Saudi Arabia. ${ }^{30-32}$ Students with severe 
menstrual pain were more at risk for the development of PMDD compared with those who had no menstrual pain. The possible explanations for this association might be menstrual pain or dysmenorrhoea that causes distress, and aggravates the emotional and behavioural responses to menstrual symptomatology and leads to the likelihood of PMDD. Menstrual pain may also increase anxiety, tension, sensitivity to rejection by others and irritability. This was supported by the studies conducted in Nigeria, ${ }^{114}$ Ethiopia, ${ }^{14} 48$ Pakistan, ${ }^{27} 28{ }^{49}$ Egypt $^{29}$ and Iran. ${ }^{42}$ The odds of developing PMDD was higher among the students who had high academic stress compared with those who had no such stress. The possible reason might be that when individuals become more stressed, their concentration in studies and coping mechanism for life events decreases, and this leads to the development of anxiety and depressive symptoms like tension, sense of difficulty to control oneself, depressed mood and irritability. With stressful life events, the level of cortisol increases, which in turn worsens the premenstrual symptoms. Premenstrual symptoms like anger and irritability may be associated with stress-related premenstrual decline in brain serotonin function, resulting in the worsening of cardinal mood symptoms. ${ }^{50}$ This was in agreement with other studies conducted in Spain, ${ }^{51}$ Iowa in the USA ${ }^{52} 53$ and India. ${ }^{54}$

\section{Strength and limitation of this study}

We used adequate sample for the study using appropriate sampling technique and data collection procedure. Since the study design was cross-sectional, it could not establish the temporal association between PMDD and identified risk factors. The severity of pain was self-reported and therefore it was subjected to social desirability and recall bias which is common to all questionnaire-based studies, as what one regards as moderate might be regarded as mild or severe by another. Comorbid mental illness was not assessed, so students with mental health problem might present symptoms overlapping with the symptoms of PMS. Since the study was conducted in a single institution, it is difficult to generalise for other students.

\section{CONCLUSION}

The magnitude of PMDD was high compared with the general population. Severe level of menstrual pain, perception of an impact of menstrual pain on academic performance and perceived stress were factors significantly associated with PMDD. It needs early screening and intervention before menstrual symptoms affect students' academic performance. Stress reduction programmes may be an effective non-pharmaceutical treatment for physical and psychological symptom relief. Therefore, it is also recommended that medical and health science students should be provided with early psychological and gynaecological counselling to prevent future complications of PMDD.

Acknowledgements We thank University of Gondar, College of Medicine and Health Sciences, for providing the chance to do this research. Our deepest gratitude goes to the study subjects for their willingness to participate in the study. We also thank data collectors and supervisors for their commitment to work hard during the data collection period.

Contributors EE: Conceived the study and participated in the statistical analysis and interpretation of data; WMG, DD and YM: Participated in the design of the study; the review of the proposal; carried out the statistical analysis and prepared the manuscript. All authors read and approved the final manuscript.

Funding The authors have not declared a specific grant for this research from any funding agency in the public, commercial or not-for-profit sectors.

Competing interests None declared.

Patient and public involvement Patients and/or the public were not involved in the design, or conduct, or reporting, or dissemination plans of this research.

\section{Patient consent for publication Not required.}

Ethics approval Ethical clearance was obtained from the Ethical Review Board of College of Medicine and Health Sciences, University of Gondar. Written informed consent was obtained from each of the participants. Confidentiality was maintained throughout the study period. Respondents who had severe symptoms of menstrual disorders were referred to the nearby clinicians.

Provenance and peer review Not commissioned; externally peer reviewed.

Data availability statement All data relevant to the study are included in the article or uploaded as supplementary information. All data were included in the manuscript including in the table. No additional data available for this study.

Open access This is an open access article distributed in accordance with the Creative Commons Attribution Non Commercial (CC BY-NC 4.0) license, which permits others to distribute, remix, adapt, build upon this work non-commercially, and license their derivative works on different terms, provided the original work is properly cited, appropriate credit is given, any changes made indicated, and the use is non-commercial. See: http://creativecommons.org/licenses/by-nc/4.0/.

\section{ORCID iDs}

Woredaw Minichil http://orcid.org/0000-0001-6897-7406

Demeke Demilew http://orcid.org/0000-0003-4564-2763

\section{REFERENCES}

1 Critchley HO, Kelly RW, Brenner RM, et al. The endocrinology of menstruation-a role for the immune system. Clin Endocrinol 2001;55:701-10.

2 Quintana-Zinn FA, Whitcomb BW, Ronnenberg AG, et al. Premenstrual symptom patterns and behavioral risk factors in young women: a cross-sectional study. J Womens Health 2017;26:1099-105.

3 Boyle GJ. Effects of menstrual cycle moods and symptoms on academic performance: a study of senior secondary school students. Br J Educ Psychol 1997;67:37-49.

4 Steiner M. Premenstrual syndrome and premenstrual dysphoric disorder: guidelines for management. J Psychiatry Neurosci 2000;25:459.

5 Steiner M, Born L. Diagnosis and treatment of premenstrual dysphoric disorder: an update. Int Clin Psychopharmacol 2000;15 Suppl 3:S5-17.

6 Ehalaiye B, Eigbefoh J, Eifediyi RA, et al. Premenstrual syndrome: prevalence, pattern and severity among female university students in Ekpoma, Nigeria. Trop J Obstet Gynaecol 2009;26:142-50.

7 Halbreich U, Borenstein J, Pearlstein T, et al. The prevalence, impairment, impact, and burden of premenstrual dysphoric disorder (PMS/PMDD). Psychoneuroendocrinology 2003;28:1-23.

8 Cohen LS, Soares CN, Otto MW, et al. Prevalence and predictors of premenstrual dysphoric disorder (PMDD) in older premenopausal women. The Harvard study of Moods and cycles. J Affect Disord 2002;70:125-32.

9 Gehlert S, Song IH, Chang C-H, et al. The prevalence of premenstrual dysphoric disorder in a randomly selected group of urban and rural women. Psychol Med 2009;39:129-36.

10 Qiao M, Zhang H, Liu H, et al. Prevalence of premenstrual syndrome and premenstrual dysphoric disorder in a population-based sample in China. Eur J Obstet Gynecol Reprod Biol 2012;162:83-6.

11 Issa BA, Yussuf AD, Olatinwo AWO, et al. Premenstrual dysphoric disorder among medical students of a Nigerian university. Ann Afr Med 2010;9:118.

12 Alemu SM, Habtewold TD, Haile YG. Mental and reproductive health correlates of academic performance among Debre Berhan University 
female students, Ethiopia: the case of premenstrual dysphoric disorder. Biomed Res Int 2017;2017:1-8.

13 Desalew Jember BD, Mihretie G. Premenstrual dysphoric disorder among female students at Assosa Techinical \& Vocational Education Training School, Assosa, Ethiopia. Prevalence. , 2017: 16, 17.

14 Tsegaye D, Getachew Y. Premenstrual dysphoric disorder and associated factors among female health science students in Wollo University, Ethiopia, 2017/18. In: Maternal health, neonatology and perinatology. 2019: 5, 8.

15 Yonkers KA, O'Brien PMS, Eriksson E. Premenstrual syndrome. The Lancet 2008;371:1200-10.

16 Baca-García E, Sánchez-González A, González Diaz-Corralero $\mathrm{P}$, et al. Menstrual cycle and profiles of suicidal behaviour. Acta Psychiatr Scand 1998;97:32-5.

17 MacKinnon PC, MacKinnon IL. Hazards of the menstrual cycle. Br Med J 1956;1:555.

18 Baca-Garcia E, Diaz-Sastre C, Ceverino A, et al. Premenstrual symptoms and luteal suicide attempts. Eur Arch Psychiatry Clin Neurosci 2004;254:326-9.

19 Takeda T, Tasaka K, Sakata M, et al. Prevalence of premenstrual syndrome and premenstrual dysphoric disorder in Japanese women. Arch Womens Ment Health 2006;9:209-12.

20 Harrison WM, Endicott J, Nee J, et al. Characteristics of women seeking treatment for premenstrual syndrome. Psychosomatics 1989;30:405-11.

21 Wang M, Seippel L, Purdy RH, et al. Relationship between symptom severity and steroid variation in women with premenstrual syndrome: study on serum pregnenolone, pregnenolone sulfate, 5 alphapregnane-3,20-dione and 3 alpha-hydroxy-5 alpha-pregnan-20-one. $J$ Clin Endocrinol Metab 1996;81:1076-82.

22 Oliveira CPMS, Kassab P, Lopasso FP, et al. Protective effect of ascorbic acid in experimental gastric cancer: reduction of oxidative stress. World J Gastroenterol 2003;9:446.

23 Cénac A, Maikibi DK, Develoux M. Premenstrual syndrome in Sahelian Africa. A comparative study of 400 literate and illiterate women in niger. Trans R Soc Trop Med Hyg 1987;81:544-7.

24 Marván ML, Díaz-Erosa M, Montesinos A. Premenstrual symptoms in Mexican women with different educational levels. J Psychol 1998;132:517-26.

25 Connolly M. Premenstrual syndrome: an update on definitions, diagnosis and management. Adv. psychiatr. treat 2001;7:469-77.

26 Colin CM, Shushan A. Complications of menstruation: abnormal uterine bleeding. In: Nathan L, ed. Current diagnosis and treatment obstetrics and gynecology. 10th edn. United States of America: McGrawHill, 2007: 572-3.

27 Pal SA, Dennerstein L, Lehert P. Premenstrual symptoms in Pakistan women and their effect on activities of daily life. J Pak Med Assoc 2011;61:763.

28 Hashim R, Ayyub A, Hameed S, et al. Premenstrual syndrome: messes with my academic performance. Pak Armed Forces Med J 2014;64:199-203.

29 Seedhom AE, Mohammed ES, Mahfouz EM. Life style factors associated with premenstrual syndrome among El-Minia university students, Egypt. ISRN Public Health 2013;2013:1-6.

30 Goweda RA, Alkot MM, Alturkistani FA, et al. Prevalence of premenstrual dysphoric disorder among medical students of Umm Al-Qura University, Makkah Al-Mukaramah, Kingdom of Saudi Arabia. World Fam Med J 2016;99:1-7.

31 Tolossa FW, Bekele ML. Prevalence, impacts and medical managements of premenstrual syndrome among female students: cross-sectional study in College of health sciences, Mekelle University, Mekelle, Northern Ethiopia. BMC Womens Health 2014;14:52.

32 Shiferaw MT, Wubshet M, Tegabu D. Menstrual problems and associated factors among students of Bahir Dar University, Amhara national regional state, Ethiopia: a cross-sectional survey. Pan Afr Med J 2014;17:246.

33 Association AP. Diagnostic and statistical manual of mental disorders. BMC Med 2013;17:133-7.
34 Dalgard OS, Dowrick C, Lehtinen V, et al. Negative life events, social support and gender difference in depression. Soc Psychiatry Psychiatr Epidemiol 2006;41:444-51.

35 Cohen S, Kamarck T, Mermelstein R. A global measure of perceived stress. J Health Soc Behav 1983;24:385-96.

36 Hussein Shehadeh J, Hamdan-Mansour AM. Prevalence and association of premenstrual syndrome and premenstrual dysphoric disorder with academic performance among female university students. Perspect Psychiatr Care 2018;54:176-84.

37 Singh A, Kiran D, Singh H, et al. Prevalence and severity of dysmenorrhea: a problem related to menstruation, among first and second year female medical students. Indian J Physiol Pharmacol 2008;52:389-97.

38 Mossie TB, Tesfaye YB, Metekiya WM, et al. Magnitude of premenstrual dysphoric disorder and associated factors among high school girls, Mekelle, North Ethiopia. Ethiop J Health Dev 2015;29:170-5.

39 Sehlo MG, Youssef UM, Mahdy RS, et al. Prevalence and symptoms of premenstrual dysphoric disorder in a sample of psychiatric patients at Zagazig university hospitals. Egypt $J$ Psychiatr 2018;39:83

40 Lee Y-J, Yi S-W, Ju D-H, et al. Correlation between postpartum depression and premenstrual dysphoric disorder: single center study. Obstet Gynecol Sci 2015;58:353-8.

41 Aryal S, Thapa B, Pant SB. Premenstrual syndrome and premenstrual dysphoric disorder in medical and nursing students of a tertiary care teaching hospital in Nepal. Nepal j. obstet. gynaecol. 2017;12:12-16.

42 Naeimi $\mathrm{N}$. The prevalence and symptoms of premenstrual syndrome under examination. J Biosci Med 2015;03:1-8.

43 Delara M, Borzuei H, Montazeri A. Premenstrual disorders: prevalence and associated factors in a sample of Iranian adolescents. Iran Red Crescent Med J 2013;15:695-700.

44 Tenkir A, Fisseha N, Ayele B. Premenstrual syndrom: prevalence and effect on academic and social performances of students in Jimma University, Ethiopia. Ethiop J Health Dev 2003;17:181-8.

45 Raval CM, Panchal BN, Tiwari DS, et al. Prevalence of premenstrual syndrome and premenstrual dysphoric disorder among college students of Bhavnagar, Gujarat. Indian J Psychiatry 2016;58:164

46 Parikh MN, Parikh NC, Parikh SK. Premenstrual dysphoric disorder in adolescent girls in Western India. Gujarat Med J 2015;70:65-9.

47 Adewuya AO, Loto OM, Adewumi TA. Premenstrual dysphoric disorder amongst Nigerian university students: prevalence, comorbid conditions, and correlates. Arch Womens Ment Health 2008;11:13-18.

48 Jember D, Duko B, Mihretie G. Premenstrual dysphoric disorder among female students at Assosa Techinical Premenstrual \& Vocational Education Training School, Assosa, Ethiopia. Prevalence. J Psychiatry 2017;16:17.

49 Nisar N, Zehra N, Haider G, et al. Frequency, intensity and impact of premenstrual syndrome in medical students. J Coll Physicians Surg Pak 2008;18:481-4.

50 Eriksson O, Wall A, Olsson U, et al. Women with premenstrual dysphoria lack the seemingly normal premenstrual right-sided relative dominance of 5-HTP-derived serotonergic activity in the dorsolateral prefrontal cortices - a possible cause of disabling mood symptoms. PLoS One 2016;11:e0159538.

51 Del Mar Fernández M, Regueira-Méndez C, Takkouche B. Psychological factors and premenstrual syndrome: a Spanish casecontrol study. PLoS One 2019;14:e0212557.

52 Hulstein PL. Premenstrual symptoms and academic stress in emerging adulthood women, 2009.

53 Gollenberg AL, Hediger ML, Mumford SL, et al. Perceived stress and severity of perimenstrual symptoms: the BioCycle study. J Womens Health 2010;19:959-67.

54 Kollipaka R, Arounassalame B, Lakshminarayanan S. Does psychosocial stress influence menstrual abnormalities in medical students? J Obstet Gynaecol 2013;33:489-93. 